\title{
EFEITO DE MISTURAS DE TURFA E BAGAÇO- DE-CANA SOBRE A PRODUÇÃO DE MUDAS DE MARACUJÁ E TOMATE
}

\author{
L.A. BIASI'; D.A.C. BILIA ${ }^{1,2}$; A.R. SÃO JỌSE'1,3 J.L. FORNASIERIי,; K. MINAMI \\ 'Pós-Graduando em Fitotecnia-ESALQ/USP, C.P. 9, CEP: 13400-970 - Piracicaba,SP. \\ ${ }^{2}$ Instituto de Botânica - IB/SP, São Paulo-SP. \\ ${ }^{3}$ Departamento de Fitotecnia e Zootecnia - UESB, Vitória da Conquista-BA. \\ 'Departamento de Ciências Agrárias-UFMS, Dourados-MS. \\ ${ }^{5}$ Departamento de Horticultura - ESALQUSSP. C.P. 9, CEP 13400-970. Piracicaba-SP.
}

\begin{abstract}
RESUMO: Com o objetivo de estudar a viabllidade da utilização de turfa e de bagaço-de-cana como substrato para a produço de mudas de tomateiro 'Rio Grande' e maracujá-amarelo realizou-se experimento, cujos tratamentos consistiram de turfa $(100 \%)$, bagaco-de-cana (100\%) e suas misturas em proporçóes volumétricas de 25,50 e $75 \%$. 0 delineamento experimental fol inteiramente casualizado com 4 repetiços. A maior quantidade de hagaço-de-cana conferiu maior porosidade e aeractho ao substrato, favorecendo a emergêncla do tomateiro e desfavorecendo a do maracujaamarelo. Para esta espécie, a emergência fol melhor nos tratamentos com malores porcentagens de turfa, onde a retenç̃o de água pelo substrato fol superfor Entretanto, a utillyaço integral de cada um dos substratos não proporcionou condiçōes adequadas ao desenvolvimento de ambas as espécies, resultando mudas piores. $O$ tratamento constituído pela mistura de $50 \%$ destes materials fol superior tanto para o maracujá como para o tomate, sendo recomendada como um bom substrato para uso horticola.
\end{abstract}

Descritores: maracujá-amarelo, tomate, Passiflora edulis f. flavicarpa, Lycopersicon esculentum, substrato

\section{EFFECT OF PEAT AND SUGAR CANE HUSK MIXTURES ON PASSION FRUIT AND TOMATO SEEDLING PRODUCTION}

\begin{abstract}
This work was carried out in order to verify the potential of peat and sugar cane husk mixtures for ' $R$ io Grande' tomato and yellow passion fruit seedling production. The treatments consisted of peat (100\%), sugar canehusk (100\%) and mirtures in the following vohume rates: 25,50 and 75\%. The statistical design was completely randomized with 4 replicates. The tomato emergence was greater with the addition of more sugar cane-husks, which increased the porosity and aeration of the substrate. The results were, however, opposite for the passion fruit emergence, which was better as peat content increased, due to the increased water retention of the substrate. The worse seedlings for both specles were obtained with peat and sugar cane-husks alone. The best treatment for passion fruit and tomato growth was the mixture at $50 \%$, therefore being recommended as a good nursery substrate.
\end{abstract}

Key Words: passion fruit, tomato, Passiflora edulis f. flavicarpa, Lycopersicon esculentum, substrate

\section{INTRODUÇÃO}

As caracteristicas do meio utilizado para produção de mudas exercem grande influência na qualidade da planta produzida (WATERS et al., 1970).

Os substratos mais utilizados compre-se basicamente de solo mineral e matéria orgânica (BACKES, 1988). Entretanto, segundo POOLE \& WATERS (1972) as caracteristicas fisicas dos solos não são as desejáveis para um substrato. Por isso inúmeros materiais vem sendo testados em sua substituição como lascas de madeira, vermiculita, argila calcinada, composto de lixo, bagaço-de-cana (CONOVER, 1967), turfa, casca-de-arroz carbonizada e maravalha (BELLÉ, 1990).
Uma vez que as condições ideais de um substrato dependem da faixa de exigência das espécies cultivadas, dificilmente se encontra um material que por si só supre todas as condiçőes para o crescimento destas plantas (GROLLI, 1991). Além de que, os materiais disponiveis apresentam uma série de problemas para as plantas e características muito diversas (BORDAS et al., 1988).

Devido a estes fatos, é preferível a mistura de dois ou mais materiais para a obtenção de um substrato adequado (BACKES et al., 1988), sendo que, os materiais adicionados em proporçoes inferiores ou iguais a $50 \%$ do volume total, são denominados condicionadores (BELLÉ, 1990). 
A turfa apresenta vantagens de uso como condjcionador melhorando as características fisicas, principalmente a redução da densidade de materiais pesados e aumento da capacidade de retenção de água (GROLLI, 1991) e químicas do substrato, como a alcalinidade e salinidade (BACKES \& KÄMPF, 1991). Entretanto, ela se constitui num recurso natural não renovável, comprometendo o seu fomecimento permanente (GROLLI, 1991).

$O$ presente trabalho foi realizado com o objetivo de avaliar a turfa, o bagaço-de-cada e misturas desses materiais em diferentes proporções volumétricas, como substrato para a produção de mudas de tomateiro e maracujá-amarelo.

\section{MATERIAL E METODOS}

Este trabalho foi realizado na área experimental e laboratório do Departamento de Horticultura da Escola Superior de Agricultura "Luiz de Queiroz", da Universidade de São Paulo, em Piracicaba, SP.

Os materiais utilizados para a composição das misturas foram turfa peneirada e bagaço-de-cana picada.

Os tratamentos testados resultaram das seguintes combinações volumétricas entre os materiais:

1)Turfa $(100 \%)$

2)Turfa (75\%) + bagaço-de-cana (25\%)

3)Turfa $(50 \%)$ + bagaço-de-cana $(50 \%)$
4)Turfa (25\%) + bagaço-de-cana (75\%)

5)Bagaço-de-cana (100\%)

$O$ delineamento experimental foi inteiramente casualizado com 4 repetiçōes e 25 sementes por parcela.

Após a mistura dos materiais, eles foram distribuídos em caixas de madeira de $70 \times 45 \times 10 \mathrm{~cm}$ que foram divididas em 8 parcelas.

As propriedades fisicas das misturas foram determinadas em laboratório de acordo com o método descrito por FRETZ et al. (1979).

Para a avaliação biológica dos substratos foram produzidas mudas de maracujá-amarelo e tomateiro da cultivar Rio Grande.

A semeadura de ambas as espécies foi realizada no dia 04 de abril de 1994, dentro de uma casade-vegetação com lateral de sombrite e cobertura plástica em forma de arco.

As avaliações das mudas de tomateiro e maracujá-amarelo foram realizadas, quando estas apresentaram tamanho suficiente para a repicagem, aos 36 e 57 dias após a semeadura, respectivamente.

A altura das mudas foi determinada do colo das plantas até o ápice meristemático e foram consideradas como folhas definitivas aquelas que possuiam mais de $1,5 \mathrm{~cm}$, excluindo as folhas cotiledonares. Para a determinação do peso seco as plantas permaneceram em estufa por 48 horas a $60^{\circ} \mathrm{C}$.

TABELA 1. Propriedades fisicas das misturas de turfa e bagaço-de-cana.

\begin{tabular}{lcccc}
\hline \hline Misturas & $\begin{array}{c}\text { Densidade } \\
\text { Úmida } \\
(\mathrm{g} /)\end{array}$ & $\begin{array}{c}\text { Espaço } \\
\text { Poroso } \\
\text { Total } \\
(\% \text { vol })\end{array}$ & $\begin{array}{c}\text { Retenção de Águá } \\
\text { na Capacidade } \\
\text { de Campo } \\
(\% \text { vol) }\end{array}$ & $\begin{array}{c}\text { Espaço de ar } \\
\text { na Capacidade } \\
\text { de Campo } \\
(\% \text { vol) }\end{array}$ \\
\hline T100 & 695 & 42,5 & 38,0 & 4,5 \\
T75 + B25 & 620 & 45,0 & 32,6 & 12,4 \\
T50+B50 & 532 & 50,0 & 31,1 & 18,9 \\
T25 + B75 & 458 & 51,2 & 20,5 & 30,7 \\
B100 & 413 & 62,5 & 13,8 & 48,6 \\
\hline \hline
\end{tabular}

' $\mathrm{T}=$ turfa; $\mathrm{B}=$ bagaço-de-cana 


\section{RESULTADOS E DISCUSSĀo}

A análise das propriedades físicas das misturas, cujos resultados encontram-se na TABELA 1, revelou caracteristicas bastante diversas entre a turfa e o bagaço-de-cana, com valores intermediários para as misturas entre estes materiais. A turfa apresentou a maior densidade, o menor espaço poroso total, a maior retenção de água e o menor espaço de ar na capacidade de campo, ao contrário do bagaçode-cana, cujo comportamento foi justamente $o$ inverso. A turfa deste experimento apresentou características diferentes da turfa gaúcha utilizada nos trabalhos de BACKES \& KÄMPF (1991), BELLÉ \& KÄMPF (1993) e KÄMPF (1993), onde a densidade seca foi inferior a $200 \mathrm{~g} / \mathrm{e}$ a úmida próxima de $400 \mathrm{~g} /$, bem inferior a densidade úmida da turfa utilizada neste trabalho que atingiu $695 \mathrm{~g} /$.

A avaliação biológica dos susbtratos permitiu um melhor entendimento do efeito das características fisicas das misturas sobre a produçăo vegetal. Ambas as espécies utilizadas foram fortemente influenciadas por estas caracteristicas (TABELAS 2 c 3).

A emergência do tomateiro ocorreu, de uma maneira geral, no $8^{\circ}$ dia após a semeadura, encontrando-se a maior porcentagem de plantas emergidas (85\%) no substrato formado por bagaco-de-cana puro, que não diferiu das demais misturas e foi superior a turfa pura, onde a emergência foi de apenas $38 \%$ (TABELA 2). Isto evidencia uma maior exigência do tomateiro $\mathrm{cm}$ acração do que em umidade para germinar (JANICK et al., 1974), pois o espaco de ar ć de aproximadamente $48,6 \%$ no bagaço-de-cana, enquanto na turfa atinge apenas $4,5 \%$ (TABELA 1 ).

Apesar da melhor emergencia do tomateiro no bagaço-de-cana puro, este não se revelou bom substrato, pois nele, juntamente com a turfa pura, as plantas apresentaram péssimo desenvolvimento, sendo inferiores aos demais tratamentos em todas as caracteristicas analisadas (TABELA 2).

As misturas entre estes materiais foram mais favoráveis à produção de mudas de tomateiro, com destaque para o tratamento com turfa e bagaço-decana em proporçбes iguais, onde foram produzidas as melhores mudas, considerando a obtenção dos maiores valores de altura $(12,4 \mathrm{~cm})$, número de folhas definitivas $(3,3)$, peso fresco da parte áerea $(927 \mathrm{mg})$ e raiz $(222 \mathrm{mg})$ e peso seco da parte aérea (158,1mg) e raiz $(26,7 \mathrm{mg})$ (TABELA 2).

Estes resultados estão em concordância com os do trabalho realizado por KÄMPF (1993), que obteve as melhores mudas de tomate 'Kada', com uma mistura formada pela combinaçăo de turfa com 50 ou $33 \%$ de casca de arroz carbonizada.

A emergência do maracujá-amarelo, que ocorreu no $12^{\circ}$ dia após a semeadura, apresentou um comportamento bastante distinto do tomateiro. A

TABELA 2. Avaliação biológica de mudas de tomateiro 'Rio Grande' produzidas em diferentes misturas de turfa e bagaco-de-cana.

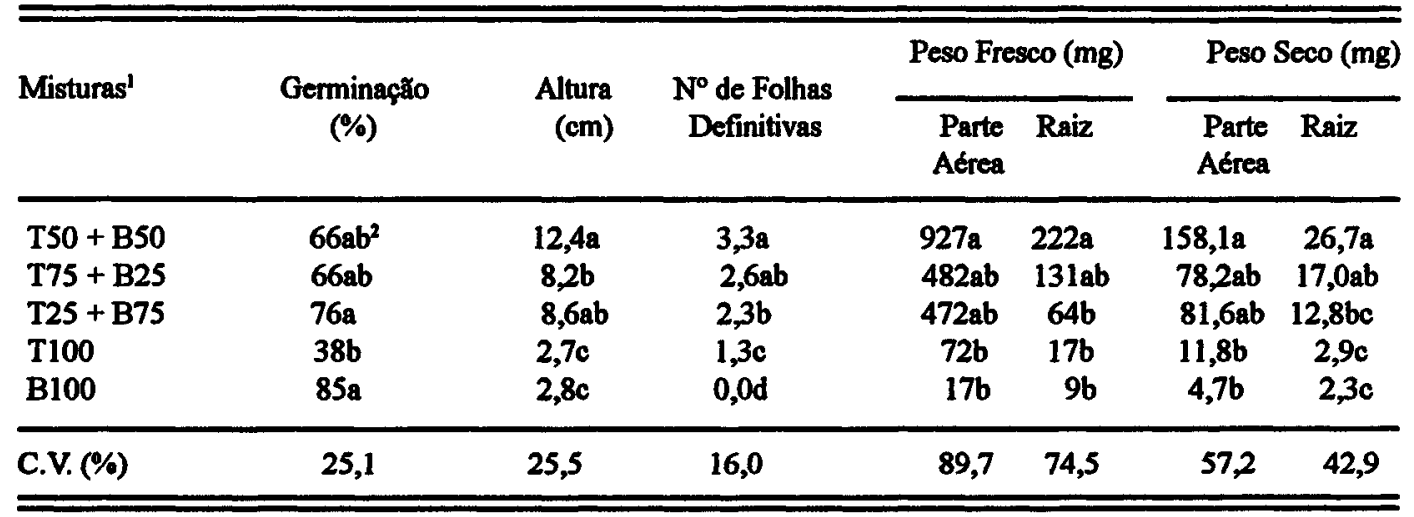

'T=turfa; B=bagaço-de-cana

${ }^{2}$ Médias seguidas pela mesma letra não diferem significativamente pelo teste de Tukey ao nível de 5\% de probabilidade. 
menor emergência, neste caso, foi verificada com o bagaço-de-cana puro ( $24 \%$ ), enquanto que com a turfa pura e sua mistura em proporções de 50 e $75 \%$, foram obtidas as maiores porcentagens de emergência (TABELA 3). Ao contrário do tomateiro, o maracujá parece ser menos exigente em aeração para germinar e mais exigente em umidade, pois a retenção de água nas misturas de turfa em proporções superiores a $50 \%$, atinge mais de $30 \%$, e no bagaço-decana é de apenas $13,8 \%$ (TABELA 1).

BELLÉ \& KÄMPF (1993) obtiveram resultados semelhantes trabalhando também com maracujá-amarelo, onde a menor porcentagem de germinação foi encontrada num meio formado de turfa $(33 \%)$ e casca de arroz carbonizada $(66 \%)$. Os autores atribuiram este fato a maior porosidade do substrato, que pode dificultar o contato da semente com o meio, diminuindo a disponibilidade de água para a germinação.

As misturas com 50 e $75 \%$ de turfa foram mais favoráveis para a produção de mudas de maracujáamarelo, praticamente não diferindo entre si. No entanto vale ressaltar a tendência das melhores mudas serem obtidas com a mistura em proporções iguais de turfa e bagaço-de-cana, onde foram obtidos os maiores valores de altura $(7,4 \mathrm{~cm})$, peso fresco da parte aérea $(978,1 \mathrm{mg})$ e peso seco da parte áerea $(149,8 \mathrm{mg})$ e raíz ( $36,7 \mathrm{mg}$ ) (TABELA 3). Além do fato de ser preferível o menor gasto de turfa, já que em termos ecológicos é um recurso natural não renovável.

Na produção de mudas de maracujá-amarelo, BELLÉ \& KÄMPF (1993) também encontraram os melhores resultados com a mistura de turfa e casca de arroz carbonizada na proporção volumétrica de 1:1.

TABELA 3. Avaliação biológica de mudas de maracujá-amarelo produzidas em diferentes misturas de turfa e bagaço-de-cana.

\begin{tabular}{|c|c|c|c|c|c|c|c|}
\hline \multirow{2}{*}{ Misturas' } & \multirow{2}{*}{$\begin{array}{c}\text { Germinação } \\
(\%)\end{array}$} & \multirow{2}{*}{$\begin{array}{r}\text { Altura } \\
(\mathrm{cm})\end{array}$} & \multirow{2}{*}{$\begin{array}{c}N^{\circ} \text { de Folhas } \\
\text { Definitivas }\end{array}$} & \multicolumn{2}{|c|}{ Peso Fresco (mg) } & \multicolumn{2}{|c|}{ Peso Seco (mg) } \\
\hline & & & & $\begin{array}{l}\text { Parte } \\
\text { Aérea }\end{array}$ & Raiz & $\begin{array}{l}\text { Parte } \\
\text { Aérea }\end{array}$ & Raiz \\
\hline $\mathrm{T} 50+\mathrm{B} 50$ & $92 a^{2}$ & $7,4 a$ & $4,3 a$ & $978,1 \mathrm{a}$ & $409,3 a$ & $149,8 \mathbf{a}$ & $36.7 \mathrm{a}$ \\
\hline $\mathrm{T} 75+\mathrm{B} 25$ & $95 a$ & $6,6 a$ & $4,5 a$ & $827,2 \mathrm{ab}$ & $266,3 \mathrm{~b}$ & $110,0 \mathrm{ab}$ & $24,2 \mathrm{ab}$ \\
\hline $\mathrm{T} 25+\mathrm{B} 75$ & $34 b$ & $5,3 \mathrm{~b}$ & $3,4 b$ & $608,0 \mathrm{bc}$ & $414,3 a$ & $76,7 b c$ & $26,4 a$ \\
\hline T100 & $83 a$ & $4,1 \mathrm{c}$ & $3,2 \mathrm{~b}$ & $354,6 \mathrm{~cd}$ & $128,7 \mathrm{c}$ & $51,3 \mathrm{~cd}$ & $11,9 b$ \\
\hline $\mathrm{B} 100$ & $24 b$ & $3,0 \mathrm{c}$ & $0,9 \mathrm{c}$ & $101,3 d$ & $121,6 \mathrm{c}$ & $16,7 d$ & $12,8 b$ \\
\hline C.V. (\%) & 12,9 & 10,1 & 7,0 & 20,9 & 21,3 & 25,1 & 25,6 \\
\hline
\end{tabular}

${ }^{1} \mathrm{~T}=$ turfa; $\mathrm{B}=$ =bagaço-de-cana

${ }^{2}$ Médias seguidas pela mesma letra não diferem significativamente pelo teste de Tukey ao nível de $5 \%$ de probabilidade.

\section{CONCLUSÕES}

1. A mistura de turfa e bagaço-de-cana em proporções volumétricas iguais constitui um bom substrato para a produção de mudas de tomate e maracujá-amarelo.

2. A turfa e o bagaço-de-cana sozinhos não são recomendados como substrato para a produção de mudas de tomate e maracujá-amarelo.

\section{REFERÊNCIAS BIBLIOGRȦFICAS}

BACKES, M.A. Composto de lixo urbano como substrato para plantas omamentais. Porto Alegre, 1988. 78p. Dissertação (Mestrado) - Unjversidade Federal do Rio Grande do Sul.

BACKES, M.A.; KÄMPF, AN. Substratos à base de composto de lixo urbano para a produção de plantas ornamentais. Pesquisa Agropecuária Brasileira, Brasilia, v.26, n.5, p.753-758, 1991. 
BACKES, M. A.; KÄMPF, A. N.; BORDAS, J. M. C. Substratos para produção de plantas em viveiros. In: CONGRESSO FLORESTAL ESTADUAL, 6., 1988, Nova Prata. Anals... Nova Prata: Secretaria da Agricultura do Rio Grande do Sul, 1988. v.1, p.665-676.

BELLE, S. Uso da turfa "Lagoa dos Patos" (Viamão/RS) como substrato hortícola. Porto Alegre, 1990. 142p. Dissertação (Mestrado) - Universidade Federal do Rio Grande do Sul.

BELLÉ, S.; KÄMPF, A.N. Produção de mudas de maracujáamarelo em substratos à base de turfa. Pesquisa Agropecudria Brasfleira, Brasília, v.28, n.3, p.385-390, 1993.

BORDAS, J.M.C.; BACKES, M.A.; KĀMPF, A.N. Caracteristicas fisicas e químicas de substratos comerciais. In: CONGRESSO FLORESTAL ESTADUAL, 6., Nova Prata, 1988. Anals... Nova Prata: Secretaria da Agricultura do Rio Grande do Sul, 1988. v.1, p.427-435.

CONOVER, C.A. Soil amendments for pot and field grown flowers. Florida Flower Grower, Florida, v.4, p.1-4, 1967.
FRETZ, T.A.; READ, P.E.; PEELE, M.C. Plant propagation laboratory manual. Minneapolis: Burgess, 1979. 317p.

GROLLI, P.R. Composto de lixo domiciliar urbano como condicionador de substratos para plantas arbóreas. Porto Alegre, 1991. 125p. Dissertaçăo (Mestrado) - Universidade Federal do Rio Grande do Sul.

JANICK, J.; SCHERY, R W.; WOODS, F.W.; RUTTAN, V.W. Plant Science. 2 ed. San Francisco: W.H. Freeman, 1974. 740p.

KÄMPF, AN. Substratos hortícolas: turfa e a casca de arroz. Lavoura Arrozeira, Porto Alegre, v.46, n.409, p.12-13, 1993.

POOLE, R.T.; WATERS, W.E. Evaluation of various potting media for growth of foliage plants. Proceedings of Florida State Horticultural Society, Miami, v.50, p.395-398, 1972.

WATERS, W.E.; LEWELLYN, W.; NESMITH, J. The chemical, physical and salinity characteristics of twenty seven soil media. Proceedings of Florida State Horticultural Society, Miami, v.83, p.482-488, 1970.

Recebido para publicação em 25.10 .94

Aceito para publicação em 16.05 .95 